\title{
ALINHAMENTO ESTRATÉGICO E INDICADORES DE DESEMPENHO: UM ESTUDO PARA A INTEGRAÇÃO DE PROCESSOS DE GESTÃO DA QUALIDADE
}

\section{STRATEGIC ALIGNMENT AND PERFORMANCE INDICATORS: A STUDY OF THE INTEGRATION OF THE QUALITY MANAGEMENT PROCESSES}

\author{
William Barbosa Vianna \\ Doutorando \\ Universidade Federal de Santa Catarina (UFSC) \\ Programa de Pós-Graduação em Engenharia de Produção (PPGEP) \\ wpwilliam@hotmail.com

\section{Edilson Giffhorn} \\ Doutorando \\ Universidade Federal de Santa Catarina (UFSC) \\ Programa de Pós-Graduação em Engenharia de Produção (PPGEP) \\ edilson.giffhorn@gmail.com

\section{Nubia Alves de Carvalho Ferreira}

\section{Doutoranda} \\ Programa de Pós-Graduação em Engenharia de Produção (PPGEP) \\ Departamento de Engenharia de Produção e Sistemas \\ nubiaf@terra.com.br
}

\section{Prof. Dr. Edson Pacheco Paladini}

Professor Titular

Universidade Federal de Santa Catarina (UFSC)

Departamento de Engenharia de Produção e Sistemas

paladini@deps.ufsc.br 


\title{
RESUMO
}

O objetivo deste artigo é estruturar indicadores de características estratégicas para os processos de gestão da qualidade ambiental a partir de processos já implantados, com vistas a promover o alinhamento entre a gestão ambiental e a gestão estratégica da organização estudada. A metodologia utilizada emprega um Estudo de Caso, apoiado pela Análise Documental, com caráter exploratório, e tem a finalidade de identificar e estruturar os indicadores de qualidade ambiental a partir de processos de gestão já adotados na organização, quais sejam, 5S, SGQ (Sistema de Gestão da Qualidade), Certificações ISO 9000 e 14000 e SIG (Sistema Integrado de Gestão). Os resultados identificam indicadores inline, off-line e on-line, que estavam implícitos ou localizados no nível operacional, que podem compor um instrumento de gestão e de controle do alinhamento estratégico que potencializa a postura da organização frente ao mercado consumidor.

Palavras-Chave: Administração Estratégica; Sistemas de Gestão da Qualidade; Indicadores de Desempenho.

\begin{abstract}
The purpose of this paper is to structure indicators with strategic characteristics to the processes of environmental quality management through the processes already implanted, in order to enhance the alignment between environmental management and the strategic management of the organization studied. The methodology employs a Case Study, supported by Documental Analysis, with exploratory character, and has the purpose to identify and structure the environmental quality indicators from management processes already adopted in the organization, namely: 5S, SGQ (Quality Management System), ISO 9000 - 14000 and SIG (Integrated Management System). The results identify in-line, off-line and on-line indicators that were implicit or situated at the operational level that can compose a tool for management and control of strategic alignment that potentiate the organization's posture against the consumer market.
\end{abstract}

Keywords: Strategic Management, Management Systems Quality, Performance Indicators. 


\section{INTRODUÇÃO}

A gestão estratégica da qualidade no setor industrial de fertilizantes depende diretamente do bom desempenho da gestão ambiental no que se refere à percepção do consumidor, dentre outras razões, porque a indústria química é a maior responsável pela dispersão de substâncias tóxicas no meio ambiente, tornando-se urgente e necessário promover mudanças na forma de tratar os problemas ambientais (ANASTAS E FARRIS, 1994).

Além disso, doenças pulmonares ocupacionais constituem um importante e grave problema de saúde pública, havendo diversos riscos da exposição associada à produção de fertilizantes. Uma vez que os processos de produção dos fertilizantes não são exatamente iguais, já que as indústrias produzem desde matéria-prima básica (mineração da rocha fosfática, síntese de ácidos sulfúrico, fosfórico e/ou amônia) até a granulação, como também produzem contaminantes ambientais distintos, com fatores de riscos diferentes, não parece adequado comparar trabalhos sobre o assunto, dada a diversidade dos processos em questão (HÜTTNER E MOREIRA, 2000).

Nesse contexto, cabe ainda considerar que a qualidade é um conceito dinâmico - ou seja, é uma noção que trabalha com referenciais que mudam ao longo do tempo, às vezes, de forma bastante rápida e acentuada (PALADINI, 2004).

Considera-se nesse contexto que Estratégia seja a criação de uma posição exclusiva e valiosa, envolvendo um conjunto diferente de atividades, ou seja, não apenas uma forma de fazer as coisas diferentes mas algo que agregue maior valor aos consumidores (PORTER, 1996, 1999).

A gestão ambiental por sua vez, é entendida como um processo contínuo e adaptativo, que necessita adequar suas metas e objetivos à proteção do ambiente, à saúde e à segurança de seus empregados, clientes e da comunidade, definindo e redefinindo estratégias e recursos para atingir os objetivos fixados para um determinado prazo, considerando a constante interação da organização com o meio ambiente externo (ANDRADE et al., 2000).

Contudo, ultimamente as restrições de mercado internacional que vem impondo barreiras não-tarifárias a produtos e empresas destituídos de bom desempenho ambiental (TIGRE, 1994; REIS, 1995; CULEY, 1998; HILL, STEPHENS E SMITH, 2003). 
Nesse sentido, Tibor e Feldman (1996), consideram que a gestão ambiental tem sido, com frequiência, reativa, fragmentada e focada em "apagar incêndios", ao invés de evitá-los, não podendo mais depender apenas de controles end-of-pipe (postura reativa da empresa), normalmente ineficientes, inadequados e mais dispendiosos, uma vez que proteção ambiental tem a ver com atitudes pró-ativas, que vão além das conformidades às regulamentações.

Segundo o Instituto Ethos (2005), de que adianta ser a primeira empresa no ranking do seu negócio, deter as melhores máquinas e tecnologia, se ela não puder contar com uma sociedade que compartilhe das mesmas perspectivas?

Tachizawa (2002) afirma que os novos tempos caracterizam-se por uma rígida postura dos clientes, voltada para a expectativa de interagir com organizações que sejam éticas, detentoras de boa imagem institucional no mercado e que atuem de forma ecologicamente responsável.

Compreende-se, assim, porque muitas empresas, tendo percebido a demanda ambiental, anunciam que seus produtos são benéficos ao meio ambiente, associando resultados isolados de alguns indicadores a um bom desempenho ambiental, não integrando processos de gestão às suas estratégias corporativas, limitando-se por vezes a "apagar incêndios" fiscais e corrigir danos à sua própria reputação quando ocorrem problemas, confundindo medidas parciais com estratégias consistentes.

\subsection{Objetivos}

Considera-se adequado do ponto de vista estratégico, o alinhamento e a integração dos instrumentos de gestão, certificações e outros processos organizacionais que, embora relevantes, quando funcionam de forma isolada podem apenas indicar que houve uma documentação suficiente para a certificação ou, apenas, meros procedimentos formais adotados em um determinado tempo, transformando em meios, os fins da qualidade.

Nesse sentido, o presente artigo centra atenção na seguinte questão: Como promover o Alinhamento Estratégico de processos de Gestão com vistas ao bom desempenho ambiental e à promoção de uma Gestão Estratégica da Qualidade?

Diante disso, o objetivo deste texto é evidenciar indicadores estratégicos DA qualidade ambiental a partir de processos já implantados, visando a promover o alinhamento entre a gestão ambiental e a gestão estratégica. 


\subsection{Metodologia}

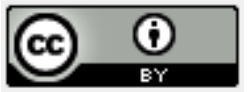

Esse trabalho, de natureza predominantemente teórica, é um Estudo de Caso caracterizado pela Análise Documental, sendo de caráter exploratório, com vistas à identificação e estruturação de indicadores da qualidade ambiental a partir de processos de gestão já implantados em uma organização.

Yin (1994) define "estudo de caso" com base nas características do fenômeno em estudo e com base em um conjunto de características associadas ao processo de coleta dos dados e às estratégias de análise dos mesmos. Para o autor, o estudo de caso é um processo de investigação empírica com o qual se pretende estudar um fenômeno contemporâneo no contexto real em que este ocorre, sendo particularmente adequado quando as fronteiras entre o fenômeno em estudo e o contexto em que ele ocorre não são claramente evidentes. Por ser difícil isolar o fenômeno em estudo do contexto em que ocorre, é normalmente necessário usar múltiplas fontes de evidência (dados) e cruzar (triangular) os diferentes dados recolhidos.

No presente trabalho, a coleta de dados se restringiu a utilizar como fonte primária a documentação de cinco processos de gestão da qualidade já implantados na organização em estudo: 5S, SGQ (Sistema de Gestão da Qualidade), Certificações ISO 9000 - 14000 e SIG (Sistema de Informações Gerenciais).

Tendo em vista que os documentos não podem ser analisados isoladamente, mas precisam ser situados a partir de uma categoria teórica, utiliza-se com unidade básica de compreensão, o constructo sistêmico de indicadores de qualidade (in-line; off-line e on-line) de Paladini (2002).

A aplicação se dá na Fosfertil S/A, empresa que atua nos segmentos de mineração, fertilizantes, insumos químicos e serviços de logística, e detém as maiores minas de fósforo em operação no Brasil. O artigo está dividido em seis seções: (1) Introdução; (2) Aspectos estratégicos do desempenho ambiental; (3) Alinhamento estratégico e indicadores de desempenho; (4) Categorias on-line, off-line e in-line para identificar indicadores de desempenho; (5) Estudo de Caso; e, (6) Considerações Finais.

\section{ASPECTOS ESTRATÉGICOS DO DESEMPENHO AMBIENTAL}

Os problemas ecológicos têm caráter universal, atingindo a todos, independentemente da classe social ou do desenvolvimento do país, ainda que os impactos sejam sentidos com maior peso pelas classes mais pobres. Problemas como poluição da água e do ar, rompimento 


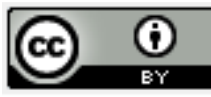

da camada de ozônio e contaminação de alimentos, contudo, não distinguem grupos sociais (Pereira e Tochetto, 2006).

Vários autores (ver, por exemplo, Reis, 1995; Maimon, 1996; Badue, Maimon e Singer, 1996; Mineiro, 1996; Nahuz, 1995; D’Avignon, 1994 e Layrargues, 2000) afirmam que o componente ambiental chegou para ficar e que a empresa moderna, indistintamente de seu porte, estrutura ou setor, tem de adaptar-se a ele, aplicando os princípios de gerenciamento ambiental para não perder espaço na competitividade empresarial.

Enfim, a questão ambiental é uma realidade que faz parte definitivamente das relações produtivas e de consumo, não se tratando de um tardio despertar de consciência ecológica dos empresários e gerentes, mas uma estratégia de negócio. De fato, esta questão pode significar vantagens competitivas ao promover a melhoria contínua dos resultados ambientais, tratando de minimizar os impactos de suas atividades e tornar todas as operações tão ecologicamente corretas quanto possível (CASTRO ET Al., 2004).

Segundo Kotler e Armstrong (2004) as pessoas estão mudando e se fidelizando às marcas com base em fatos como a reputação da empresa como defensora do ambiente. $\mathrm{O}$ aumento da conscientização da sociedade em relação à conservação ambiental tem acarretado tanto pressões governamentais quanto de entidades não governamentais (VALLE, 2005).

Bernardi (2003) enfatiza que o sucesso de uma empresa está diretamente relacionado à percepção do mercado quanto à imagem que ela cria, sendo que a sociedade participa de muitas questões ambientais, sejam de cunho social, econômico ou político e o cliente está sendo informado constantemente, através da mídia, de muitas causas e efeitos da negligência empresarial que impacta sobre o meio ambiente.

Por sua vez, um bom desempenho ambiental auxilia no reforço da reputação e da marca e, ao contrário, problemas e acidentes ambientais irão influenciar negativamente para o conceito de uma empresa junto à sociedade (MOURA, 2004).

Além disso, May, Lustosa e Vinha (2003) salientam que alguns países estão passando a adotar barreiras não-tarifárias ambientais, justificando que os países em desenvolvimento possuiriam leis ambientais menos rigorosas, resultando em custos mais baixos, também chamados de dumping ecológico, praticando menores preços que o mercado internacional.

Por outro lado, há que se considerar o conceito mais geral da qualidade. De simples aplicação de Estatística Básica, um simples modelo de controle ou um conjunto de 


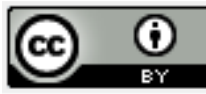

mecanismos de inspeção, a qualidade evoluiu para avançadas estratégias de produção, ganhando dimensões mais amplas, envolvendo o mercado consumidor. Essa satisfação é mais bem representada pela noção na adequação ao uso defendida por Juran (1991) e de minimização de perdas à sociedade de Taguchi (1990).

As ações de uma organização que assume responsabilidade pelos impactos de suas atividades sobre a sociedade e o meio ambiente são consistentes com os interesses da própria sociedade e do desenvolvimento sustentável; são baseadas no comportamento ético, conformidade com a lei e integradas às atividades diárias da organização (BELINKY, 2006).

Os dados confirmam a idéia de que empresas visionárias aceitam prontamente sua responsabilidade ambiental, vendo esse tipo de ação como uma oportunidade de negócio (KOTLER \& ARMSTRONG, 2004).

Respostas a questões como "em que medida os processos de gestão afetam o meioambiente e a percepção do mercado consumidor?” remetem à relação dos processos internos das organizações com o ambiente externo que impactam em objetivos estratégicos, influenciados pela noção de prevenção e adequação às expectativas do ambiente externo.

Esse processo é essencialmente dinâmico. De fato, considera-se que o alinhamento estratégico por meio da integração dos sistemas chave, dos processos e das respostas às mudanças no ambiente externo deve ser constantemente aperfeiçoado (LABOVITZ E ROSANSKY, 1997).

Alinhamento estratégico pode ser definido como um processo ou como um resultado que a organização deve buscar por meio de um ajuste adequado ao seu ambiente e, ainda, a adaptação e organização dos processos para que dêem sustentação ao próprio alinhamento (MILES E SNOW, 1984).

Um ajuste com características estratégicas dos processos organizacionais, ou seja, um alinhamento estratégico envolve uma medida de adequação entre a estratégia adotada pela organização, seu contexto externo e seus processos internos, sendo que quanto maior for essa adequação, maior o alinhamento estratégico (CORDEIRO, 2005).

Várias concepções de alinhamento estabelecem a sua relação com a melhoria do desempenho organizacional, enfatizando a idéia de ajuste (fit) externo e interno da organização às variações circunstanciais do ambiente (BEAL E YASAI-ARDEKANI, 2000; PRIETO, 2006; PRIETO \& CARVALHO, 2004). 
A Figura 1 ilustra a interação entre processos, elementos estratégicos e o desempenho ambiental.

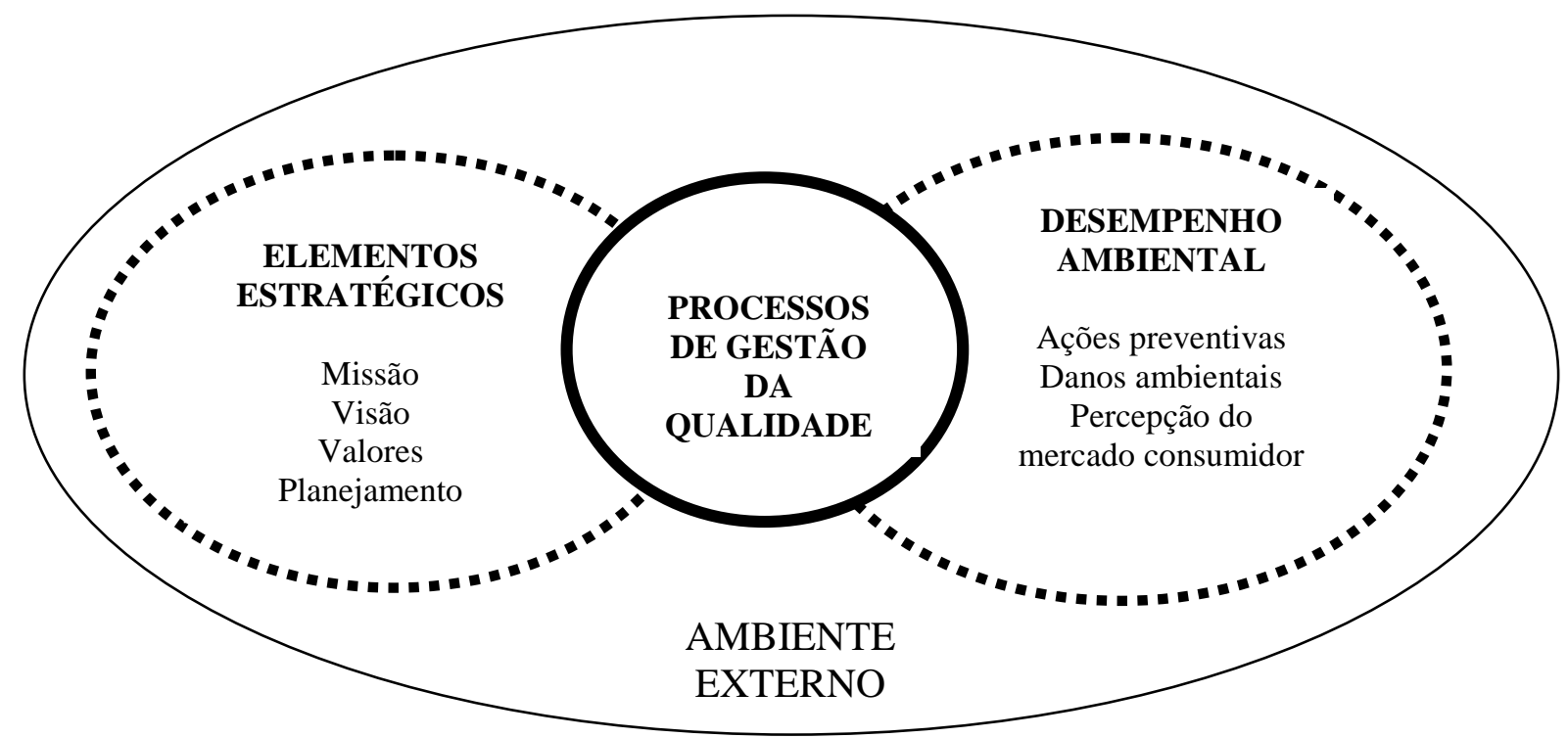

Figura 1: Representação da relação entre processos, elementos estratégicos e desempenho ambiental.

Fonte: autores

Nesse artigo considera-se que a identificação de indicadores de desempenho ambiental a partir de processos já implantados contribui para o alinhamento estratégico.

Uma vantagem de identificar indicadores apropriados para o alinhamento estratégico é distinguir-se daqueles que abusam na auto-concessão de selos verdes e certificações cujos indicadores não são integrados, demonstrando que nada mais são do que rótulos nas embalagens atestando qualidades ambientais muitas vezes questionáveis, iludindo o consumidor por meio de estratégias escusas de marketing ecológico (REIS, 1995; HURTADO, 1996/7; WEISS, 1997).

\section{ALINHAMENTO ESTRATÉGICO E INDICADORES DE DESEMPENHO}

Apesar de, por muito tempo, a qualidade ser conceituada como um conjunto de elementos internos às organizações, verifica-se que o conceito tem um significado bem mais amplo, que incorpora a relação da organização com o ambiente externo no seu entorno e, indo mais além, criando mecanismos que tendem a envolver todos os recursos das organizações de forma sistêmica (PALADINI, 2008).

Apesar de por muito tempo a qualidade ser conceituada como um conjunto de elementos internos às organizações se verifica que o conceito tem um significado bem mais 
amplo, que incorpora a relação da organização com o ambiente externo ao seu entorno e, indo mais além, cria mecanismos que tendem a envolver todos os recursos das organizações de forma sistêmica (PALADINI, 2008).

E somente abordagens sistêmicas e integradas poderão atender às demandas concernentes às relações de trabalho, aos processos de produção e consumo, à saúde dos indivíduos e ao meio ambiente (FRANCO, 2002).

Uma boa gestão ambiental, assim, se dá por uma abordagem sistêmica da realidade, pois os problemas ambientais não podem ser compreendidos de forma isolada; ao contrário, são interligados e interdependentes, como prevê o paradigma holístico (SCHENINI, 1999).

Robles Jr. e Bonelli (2006) consideram que a Qualidade Ambiental é inseparável da Qualidade Total, e, por isso, afirmam que os instrumentos utilizados para alcançar Qualidade Ambiental são similares àqueles utilizados pela empresa para garantir sua qualidade de produção: treinamento, plano de ação, controle da documentação, organização e limpeza, inspeções e análises periódicas da situação.

Os modelos de Avaliação de Desempenho de cada organização, porém, devem reduzir o seu potencial de generalização, e ser personalizados, para que o objetivo de criar as condições para o uso das melhores práticas e a excelência seja alcançado (ENSSLIN, 2001).

Para Ensslin et al. (2007), no entanto, muitas foram as organizações que construíram sistemas de Avaliação de Desempenho centrados em processo de coleta de dados, por vezes até sofisticados, porém sem fornecer os resultados esperados, apesar de parecer tão bem planejado, programado e operacionalizado. O equívoco estava em avaliar o que era fácil de medir ou estava disponível em termos de dados, não o que era necessário medir.

Diferentes autores como Skinner (1986), Keeney (1992), Neely, Gregory e Platts (2005), entre outros, apontam para necessidade do desenvolvimento do desempenho por meio de indicadores personalizados, associados ao contexto a ser avaliado.

Outros autores, como Tangen (2003), Denton (2005), Neely e Powell (2004) vão mais além ao considerar que a adoção de medidas que se dizem aplicáveis a todas as organizações, ou a todas de um mesmo setor, uma vez que resolver os problemas de desempenho por meio do uso de medidas genéricas pré-existentes, por serem mais fáceis de medir, é um erro estratégico.

Para Robles Jr. e Bonelli (2006), a apresentação e utilização de indicadores de desempenho ambiental são importantes passos em um processo de Avaliação de Desempenho, 
pois estes procurarão sintetizar as informações quantitativas e qualitativas relacionadas ao seu desempenho ambiental.

Dessa forma, o que é novo na avaliação de desempenho é o reconhecimento da necessidade de criar uma visão sistêmica, formal, que integre os objetivos estratégicos aos indicadores de desempenho táticos e operacionais, permitindo: (i) compreender as conseqüências de variações dos indicadores de desempenho nos objetivos estratégicos e vice versa; (ii) criar alinhamento de esforços orientados para o que necessita ser mensurado para controlar a performance de objetivos estratégicos; (iii) mudar o foco de medir o desempenho de indicadores selecionados segundo a disponibilidade e facilidade de mensuração (quantitativos e disponíveis), enfatizando a identificação do é importante; e, (iv) integrar os indicadores, estabelecendo compensações entre si, fundamentando e mensurando simultaneamente sua participação nos níveis operacional, tático e estratégico do contexto da organização (ENSSLIN et al., 2007).

A mensuração por meio de indicadores não é um fim em si mesma, mas um instrumento para um gerenciamento mais efetivo que contribui para o alcance de propósitos gerenciais específicos (AMARATUNGA; BALDRY, 2002).

Independentemente da forma de operacionalizar a mensuração, porém, o sucesso da implementação de um sistema de avaliação de desempenho reside na correta escolha das medidas (DENTON, 2005).

Por isso, devem ser concentrados os esforços em poucos indicadores. E que eles sejam representativos da estratégia, porque o importante é medir o que é relevante sob aspectos específicos. Dessa forma, antes de investir em avaliações de qualquer natureza é imprescindível identificar seu grau de importância e as informações que possam viabilizá-las.

Nesse sentido, os processos implantados podem fornecer informações úteis ao alinhamento de processos de gestão ambiental e gestão estratégica, e um conjunto integrado de indicadores pode ser identificado a partir de um constructo sistêmico de análise dos dados disponíveis nos documentos implantados numa organização. 


\section{CATEGORIAS ON-LINE, OFF-LINE E IN-LINE PARA INDICADORES DE DESEMPENHO}

O processo de categorização que consiste no trabalho de classificação e reagrupamento das unidades de registro em número reduzido de categorias tem o objetivo de tornar inteligível a massa de dados e sua diversidade (FONSECA JÚNIOR, 2005, p. 298).

Nesse sentido, Paladini (2002) categoriza a organização em três ambientes ou dimensões de indicadores: o processo produtivo em si (ambiente in-line); o suporte ao processo (ambiente off-line) e as relações da organização com o mercado (ambiente on-line). Independentemente da categoria, o autor indica que as características dos indicadores devem ser: objetividade, clareza, precisão, viabilidade, representatividade, visualização, ajuste, unicidade, alcance e resultados.

O ambiente in-line relaciona-se com a produção da qualidade do bem ou serviço, associado diretamente no processo produtivo. Neste caso são priorizados esforços para a correção e prevenção de defeitos nos métodos de trabalho, dos materiais e dos equipamentos utilizados e para a organização do processo produtivo em si (Gestão da Qualidade no Processo).

$\mathrm{O}$ ambiente off-line caracteriza-se pelas atividades e funções de suporte ao processo produtivo, que podem ser acionadas quando necessárias tendo, assim, participação indireta na produção de um bem ou serviço. Esta participação, contudo, está diretamente ligada à qualidade, devendo também ser alvo de esforços de melhoria.

Ainda segundo Paladini (2002), os indicadores on-line são os mais abrangentes por incluir os demais (off-line e in-line). O objetivo dos indicadores dessa dimensão é o de medir as relações da organização com o mercado, visto que esses salientam as atitudes da empresa frente às mudanças do mercado e medem a eficácia da organização. O ambiente on-line está orientado para o ambiente externo, ou macro ambiente, que gera para a empresa oportunidades e/ou ameaças e define como esta pode se capacitar para reagir às mudanças positivas e/ou negativas deste cenário.

A ênfase ao ambiente on-line atende efetivamente à demanda do mercado, tendo como resultado a maior adequação do produto ao uso a que se destina. E até mais do que isso - é para lá que o esforço é dirigido, captando o mais rapidamente possível alterações em preferências, hábitos ou comportamentos de consumo, de modo a repassá-las ao processo 


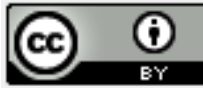

produtivo de forma a adaptar, no menor espaço de tempo, o processo à demanda, criando um produto sempre adequado à finalidade a que se dirige (CARVALHO \& PALADINI, 2006).

Dessa forma, identifica-se que os indicadores on-line são os mais adequados para promover o alinhamento estratégico dos processos de qualidade, tendo em vista suas características de comunicação e interação entre o ambiente externo e a organização produtiva, representando-se tal relação pelo atendimento aos requisitos do mercado consumidor. Figura 2 exibe a as três dimensões para uma gestão integrada da qualidade.

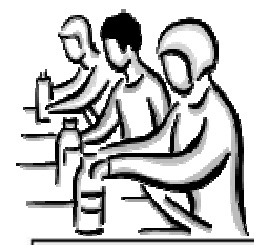

Indicadores in-line \begin{tabular}{|l|l|l|l|l|}
\hline Elemento & Fator & Medida & Status Quo & Meta \\
\hline
\end{tabular}

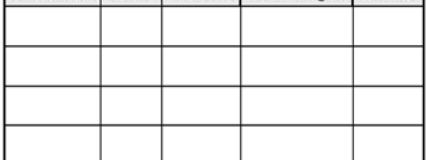

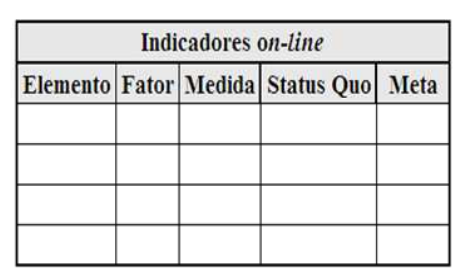
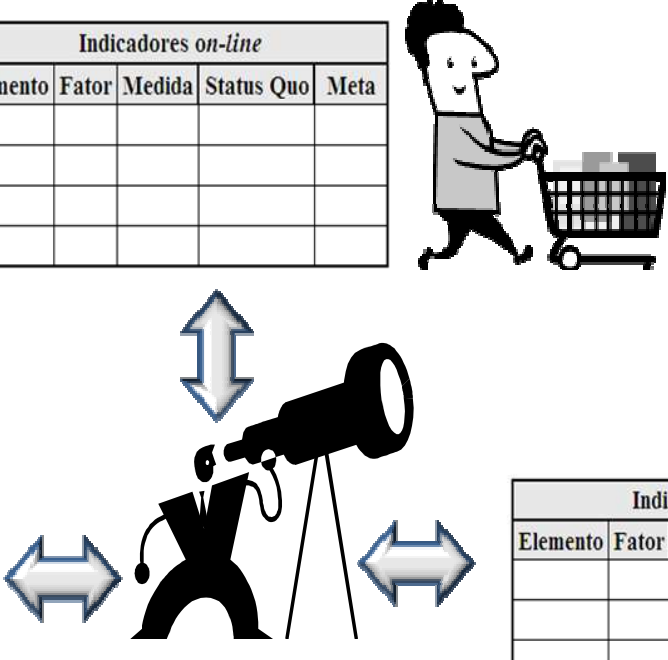

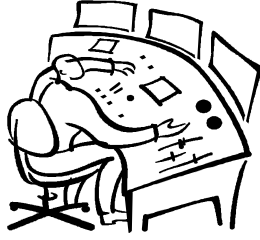

Indicadores off-line Elemento Fator Medida Status Quo Meta

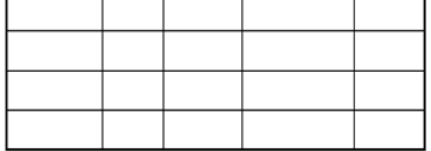

Figura 2: Três ambientes da Qualidade e composição dos indicadores

Fonte: autores

Conforme pode ser constatado, para uma efetiva gestão estratégica da qualidade ambiental, há a necessidade de integrar os diversos ambientes por meio de indicadores, sendo que o sistema de avaliação de desempenho da organização deve ser elaborado de tal forma a contemplar indicadores dos três ambientes, in-line, off-line e on-line. Somente dessa maneira serão obtidas ações sinérgicas que conduzam ao alcance da estratégia organizacional.

Paladini (2002, p. 49) acrescenta que um indicador fica perfeitamente definido se forem associados a ele dois conjuntos de dados: a) a relação do indicador com o ambiente de avaliação; para tal, é necessário associar ao indicador quatro informações básicas: objetivo; justificativa; ambiente e padrão; b) a estrutura do indicador: para tal, três componentes básicos devem ser considerados: elemento; fator; medida. 
Uma vez construídos os indicadores que atendam às propriedades e classificações expostas, pode-se elaborar planos de ações que permitam uma melhor gestão da Qualidade Ambiental que conduza ao alcance dos objetivos estratégicos da organização.

A partir dos dados coletados, poder-se-á avaliar a qualidade a partir de indicadores que, conforme Paladini (2002, p. 41), são os elementos básicos da avaliação da qualidade com dois componentes básicos: a) devem ser mensuráveis; b) medem o impacto das ações na satisfação dos consumidores e clientes.

\section{ESTUDO DE CASO: INDICADORES DE DESEMPENHO NA EMPRESA DE FERTILIZANTES FOSFATADOS S.A.}

A Fertilizantes Fosfatados S.A. - Fosfertil é uma empresa que atua nos segmentos de mineração, fertilizantes, insumos químicos e serviços de logística. A empresa detém as maiores minas de fósforo em operação no Brasil e as maiores reservas comprovadas. Em seu ambiente de operações atuam a Petrobras, Vale, Anglo American, Galvani, Bunge, dentre outras.

Seguindo a tendência mundial, a indústria brasileira de matérias-primas para fertilizantes tornou-se heterogênea e constituída por poucas empresas de grande porte, intensivas em capital, integradas ou semi-integradas, com várias empresas de menor porte, formando um oligopólio em que as economias de escala e as condições de acesso à matériaprima prevalecem como vantagens competitivas.

O mercado nacional de matérias-primas para fertilizantes tem enfrentado grandes transformações nos últimos anos a partir da privatização das estatais do setor, ocorrida na década iniciada em 1990, que forçou as empresas a modernizarem sua gestão em nome da sobrevivência. Essa necessidade de reestruturação ocorreu em consequiência da entrada no mercado nacional de empresas estrangeiras que vieram disputar e oferecer produtos e serviços em atendimento às demandas dos consumidores, investindo em atualizações tecnológicas, processos gerenciais e administrativos e na qualificação de seus colaboradores.

Já na década iniciada em 2000, o setor é afetado por fatores internos e externos. O fator externo se deu pelo aumento da demanda por commodities, especialmente pela China, que impulsionou a produção de alimentos, e por consequiência, o consumo de fertilizantes.

Como conseqüência, o consumo de fertilizantes no país passou de 20,2 para 24,6 milhões de toneladas no período entre 2005 e 2007 . Grande parte, porém, ainda é suprida por 
importações, pois a produção nacional passou de 8,5 para 9,8 milhões de toneladas no mesmo período (NOGUEIRA, 2008).

\subsection{A Fosfertil S/A}

A Fosfertil S/A foi criada como estatal em 1977 com o objetivo de promover a pesquisa, lavra, concentração e comercialização da rocha fosfática da jazida de Patos de Minas (MG). Posteriormente, a empresa incorporou a Mineração Vale do Paranaíba de Tapira e a Fertilizantes Vale do Rio Grande S.A. de Uberaba, ambas localizadas no estado de Minas Gerais.

Na década de 1980, investimentos realizados em sua verticalização tornaram-na a mais complexa indústria do ramo na América Latina (LOPES, 1988). A década seguinte ficou marcada pela privatização da Fosfertil e pela sua expansão, obtida ao adquirir outras empresas do ramo. Deste modo, a Fosfertil é resultado da privatização e posterior rearranjo acionário de empresas estatais e privadas. O holding Fertifós é composta por três grandes empresas multinacionais (Bunge, Mosaic e YARA), e outras menores.

O Complexo Industrial de Uberaba (CIU), uma das oito unidades da Fosfertil, produz ácidos sulfúrico, fosfórico e fluossilícico; fosfato de monoamônio; superfosfato simples; superfosfato triplo e granulado. Como matéria-prima, utiliza a rocha fosfática que recebe via mineroduto, sendo a amônia e enxofre importados.

A unidade de Uberaba está localizada às margens da BR 050, ao lado do Rio Grande, que divide os estados de Minas Gerais e São Paulo, e de um ramal ferroviário. Sua localização é considerada estratégica desde sua instalação, por ficar situada próxima ao principal centro consumidor de fertilizantes fosfatados do país, a região Centro-Oeste, em que predomina o cerrado, maior área produtiva de grãos atualmente no país.

A visão da empresa é: "Ser reconhecida como a melhor empresa no suprimento de produtos às indústrias de fertilizantes e químicas e na prestação de serviços de logística" Sua missão: "Agregar valor competitivo às indústrias de fertilizantes e químicas, através da excelência dos nossos produtos e serviços, atendendo às expectativas dos acionistas, empregados e das comunidades com as quais interagimos".

O estudo de Ferreira (2006) identificou como Política do Sistema Integrado de Gestão (SIG): (i) Melhorar continuamente o desempenho do SIG de forma sustentável e agregando valor à empresa; (ii) Atender aos requisitos das partes interessadas, buscando satisfazer suas 
necessidades e expectativas; (iii) Cumprir legislações e outros requisitos associados às suas atividades, produtos e serviços; (iv) Assegurar melhorias nos processos, equipamentos, instalações e no desenvolvimento humano, visando a conservação do patrimônio, dos recursos naturais e a prevenção da poluição, de lesões, de doenças e de quaisquer impactos adversos.

Para ajustar a indústria à realidade do mercado aberto e à competição externa, nos quais está presente a perda de margens decorrentes da necessidade de redução de preços visando fazer frente às importações, foram tomadas ações de: (i) redução de custos via terceirização; (ii) intensificação de automação; (iii) redução do endividamento; (iv) adoção de plantas produtivas com padrões internacionais; (v) ações preventivas em segurança, saúde e meio ambiente.

A Fosfertil, após sua privatização, investiu em melhorias organizacionais, administrativas e produtivas, o que permitiu o aumento da produção, a redução de custos e o enxugamento do quadro de funcionários.

Três fases foram fundamentais em sua reestruturação: (i) reorganização estrutural e administrativa; (ii) investimentos na melhoria dos processos e foco em resultados, efetuados por meio da atualização tecnológica; e, (iii) ênfase nos recursos humanos, saúde, segurança, qualidade e meio ambiente, certificações de qualidade e Sistema Integrado de Gestão.

\subsection{Análise documental dos processos de gestão da qualidade e identificação dos}

\section{indicadores}

Segundo Ferreira (2006) o início do programa integrado de qualidade se deu com a difusão da importância da qualidade para a empresa, processo que conduziu à adoção do programa do 5S, à implantação do SGQ e à certificação ISO 9000. Em 2000 iniciou-se a preparação para a certificação ISO 14000. Em 2002, foi implantado o SIG como uma estratégia guarda-chuva para a gestão da qualidade, do meio ambiente, da saúde e da segurança do trabalho.

A análise documental realizada revelou que a empresa divulga em seus relatórios de gestão alguns dos processos dos quais se vale para o seu Sistema Integrado de Gestão (SIG), bem como um ou outro resultado de seu desempenho ambiental obtidos desses processos.

Tendo em vista o alcance de sua visão quanto ao "reconhecimento" e a sua missão quanto ao "atendimento de expectativas", e conseqüentemente, uma melhoria em seu posicionamento estratégico junto ao mercado consumidor, outros indicadores podem ser 


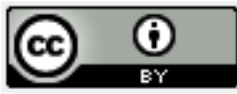

identificados em seus documentos, que podem tanto promover o Alinhamento Estratégico quanto evidenciar a melhoria no desempenho ambiental, indo além do que já realiza.

Para que o conteúdo dos documentos fosse interpretado, a análise por parte dos autores se deu na direção ou na determinação da categoria analítica conceitualmente especificada (in-line; off-line; on-line) que, nesse caso, auxiliou e orientou o agrupamento do material, ou seja, os aspectos que aparecem com certa regularidade nos documentos são a base para a ligação das informações nas categorias utilizadas (GUBA E LINCOLN, 1981; LUDKE E ANDRÉ, 1986; MILES E HUBERMAN, 1994; OLIVEIRA, 2004).

No Quadro 1 estão relacionados os indicadores in-line cujas informações podem ser obtidas mediante os processos já implantados. Note-se que a estrutura dos indicadores obedece ao critério da formulação de elementos, fatores e medidas como componentes básicos de cada indicador (PALADINI, 2008).

\begin{tabular}{|c|c|c|c|}
\hline \multicolumn{3}{|c|}{ INDICADORES IN-LINE } \\
\hline \multirow{2}{*}{ Elemento } & \multirow{2}{*}{ Fator } & \multicolumn{2}{c|}{ Medida } \\
\cline { 2 - 4 } & & Status quo & Meta \\
\hline Desperdício e perdas & Fora da especificação/especificado & $\%$ mês & $\%$ mês \\
\hline Consumo de Água & Água consumida/produção da unid. & $\mathrm{m} 3 /$ ton. & $\mathrm{m} 3 /$ ton. \\
\hline Consumo de Energia & Energia/produção da unidade & Kw/Un. Prod. & Kw/Un. Prod. \\
\hline Custo do Setup & Custo de Setup/ unid. produção & \$X Setup /Unid. & \$ X Setup /Unid. \\
\hline $\begin{array}{c}\text { Afastamentos por } \\
\text { acidente de trabalho }\end{array}$ & Afastamentos / Dias trabalhados & Afastam./dias trab. & 0 \\
\hline
\end{tabular}

QUADRO 1: Indicadores in-line.

Fonte: Autores.

O indicador que avalia o "desperdício com perdas no processo" visa reduzir a produção fora das especificações, e assim, aumentar a adequação ao uso do produto entregue aos clientes, possuindo, portanto, caráter estratégico.

Com o indicador para "água consumida no processo" procura-se racionalizar a captação deste recurso de grande impacto ambiental, cuja redução, no caso da empresa pesquisada, torna-se estratégica devido ao projeto de lei estadual de taxação de sua utilização.

Ao mensurar o "desperdício de energia" tem-se como preocupação o aperfeiçoamento do processo produtivo para a melhor utilização do uso deste recurso. Seu uso mais racional 


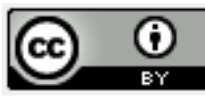

possui reflexos ambientais ao diminuir a pressão da demanda pelo aumento da capacidade geradora da matriz energética nacional.

Com a mensuração da "capacidade produtiva dos recursos" objetiva-se gerir o processo para aumentar a competitividade dos produtos no mercado, contribuindo deste modo com o alinhamento estratégico da empresa.

O indicador que mede "efluentes produzidos no processo" justifica-se devido ao fato de possuir impacto direto na qualidade ambiental e refletir a qualidade do processo produtivo pela análise do volume e tipo de resíduos gerados.

No Quadro 2 estão apresentados os indicadores off-line construídos.

\begin{tabular}{|c|c|c|c|}
\hline \multicolumn{4}{|c|}{ INDICADORES IN-LINE } \\
\hline \multirow[t]{2}{*}{ Elemento } & \multirow[t]{2}{*}{ Fator } & \multicolumn{2}{|c|}{ Medida } \\
\hline & & Status quo & Meta \\
\hline Adesão treinamento & Solicitados/atendidos & $\%$ ano & $\%$ ano \\
\hline $\begin{array}{l}\text { Responsabilidade } \\
\text { Compartilhada }\end{array}$ & Voluntários EMQs/colaboradores & $\%$ & $\%$ \\
\hline $\begin{array}{c}\text { Adequação programas de } \\
\text { Qualidade Ambiental }\end{array}$ & Não conformidades/auditoria SGA & No não conf./ audit. & 0 \\
\hline $\begin{array}{l}\text { Conscientização melhoria } \\
\text { contínua }\end{array}$ & Sugestões voluntárias/implantadas & $\%$ semestre & $\%$ semestre \\
\hline $\begin{array}{c}\text { Incentivo } \\
\text { desenvolvimento pessoal }\end{array}$ & Promoçoes alcançadas/efetuadas & $\%$ ano & $\%$ ano \\
\hline $\begin{array}{l}\text { Consciencia ecológica } \\
\text { colaboradores }\end{array}$ & $\begin{array}{l}\text { Resíduos reciclados/resíduos } \\
\text { operacionais produzidos }\end{array}$ & $\% /$ mês & $\% /$ mês \\
\hline
\end{tabular}

QUADRO 2: Indicadores off-line.

Fonte: Autores.

O indicador da "aderência dos treinamentos" foi estruturado com o objetivo de avaliar o grau de aderência dos treinamentos às solicitações feitas, e assim, possui reflexos no aumento da capacitação e motivação dos colaboradores.

Já ao se medir a "responsabilidade compartilhada", o que se quer é avaliar a sinergia existente entre equipes pela conscientização de que a responsabilidade pelos resultados pertence a todos os envolvidos nos processos. 


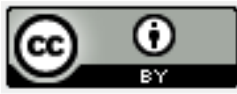

Com o indicador "adequação programas da qualidade" se espera obter um instrumento que permita o realinhamento das ações da gestão da qualidade aos objetivos estratégicos da empresa.

O indicador "conscientização melhoria contínua" procura avaliar os estímulos da organização à criatividade de seus colaboradores, por meio da geração, análise e adoção de sugestões de simplificações nos procedimentos e processos.

Ao se medir o "incentivo ao desenvolvimento pessoal" o que se quer é avaliar se os treinamentos disponibilizados causarão retorno aos treinados em perspectivas de evolução na carreira profissional, e assim, resultar no aumento da motivação.

Já o indicador "consciência ecológica colaboradores" irá avaliar ações cotidianas de cunho ecológico que contribuam para a reciclagem de resíduos gerados pelas atividades de apoio.

Os indicadores on-line propostos estão exibidos no Quadro 3.

\begin{tabular}{|c|c|c|c|}
\hline \multicolumn{2}{|c|}{ INDICADORES IN-LINE } & Fator & Medida \\
\cline { 2 - 4 } Elemento & Status quo & Meta \\
\hline Eficácia Planejamento ações & Ações preventivas realizadas/Ações preventivas & $\%$ ano & $\%$ ano \\
\hline Melhoria continua de gestão & Aperfeiçoamentos adotados/Sugeridos & $\%$ ano & $\%$ ano \\
\hline Vulnerabilidade energia & Energia Consumida/energia gerada & kW mês & kW ano \\
\hline Potencial de Comercialização de & Fosfogesso comercializado/Fosfogesso produzido & $\%$ ano & $\%$ ano \\
\hline subprodutos & & & $\%$ ano \\
\hline Potencial de comercialização de & Resíduo de Lagoa de Tratamento (RLT) & & $\%$ ano \\
\hline Lucratividade Ambiental & Receita comercialização resíduo/Receita total & R\$ ano & R\$ ano \\
\hline
\end{tabular}

QUADRO 3: Indicadores on-line.

Fonte: Autores.

Ao se utilizar o indicador "eficácia do planejamento de ações", tem-se como preocupação principal os resultados obtidos com as ações planejadas ao se agir preventivamente, ao invés de reativamente. 


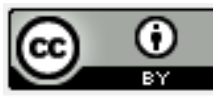

O indicador "melhoria contínua da gestão" enquadra-se na própria conceituação moderna do que seja a qualidade, um processo contínuo de maior adequação às demandas dos clientes.

Já a "vulnerabilidade do fornecimento de energia" possui caráter estratégico ao procurar blindar a empresa contra eventuais faltas de fornecimento de energia, como também possui características ambientais, ao objetivar o aumento da geração própria.

O indicador "potencial de comercialização de subproduto" (fosfogesso comercializado /fosfogesso produzido) também possui o viés estratégico. Isto se dá porque o fosfogesso é um resíduo industrial descartado normalmente pelas empresas concorrentes, mas que no presente caso é comercializado como gesso agrícola.

Nesse caso, o crescimento de sua comercialização acarreta vários benefícios à empresa, já que atualmente somente uma pequena parcela é vendida, porém sua produção gira em torno de milhões de toneladas geradas ao ano. O volume é tal que sua estocagem se dá em outro terreno próximo à fábrica, formando uma pilha com mais de 25 metros de altura.

Com "lucratividade ambiental" se procura obter um quadro que reflita os ganhos com a comercialização de produtos cujo foco principal era originalmente o atendimento de requisitos ambientais, e que passou a ser o aproveitamento de uma oportunidade de negócio.

A análise do caso fosfértil permitiu identificar que a documentação de processos implantados de gestão da qualidade é uma fonte primária relevante para a identificação de valores, interesses e objetivos explícitos e implícitos da organização e pode ser utilizado em empresas de semelhante natureza e finalidade. .

\section{CONSIDERAÇÕES FINAIS}

$\mathrm{O}$ artigo identificou e estruturou indicadores estratégicos de qualidade ambiental a partir da análise documental referente aos processos já implantados na Fosfertil S/A.

A pergunta que orientou o estudo "como promover o Alinhamento Estratégico de processos de gestão com vistas ao bom desempenho ambiental e à promoção de uma Gestão Estratégica da Qualidade" foi respondida com a identificação e estruturação de alguns indicadores (Quadros 1, 23 ) que podem ser integrados à gestão da empresa promovendo tanto o referido alinhamento como uma melhor divulgação dos resultados ambientais para o mercado. 


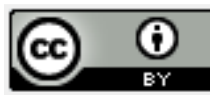

A utilização dos indicadores também pode capacitar a empresa a promover o alinhamento entre seus objetivos estratégicos e os fatores sócio-ambientais, integrando os sistemas de gestão com as certificações recebidas e outros processos utilizados no SIG (Sistema de Integrado de Gestão).

Uma vez construídos e alimentados os scorecards de indicadores, já se dispõe de um instrumento e informações capazes de promover maior precisão à tomada de decisões.

A adoção e o acompanhamento dos indicadores favorecem a economia de recursos da organização ao se evitar métodos de tentativa e erro, retrabalho, desperdício de recursos humanos assim como potencializa ações que favorecem o sucesso da adequação dos resultados aos objetivos estratégicos. Além disso, a empresa poderá dispor de melhores informações para comunicar resultados aos seus stakeholders.

Por fim, outros estudos mais em nível direto de gestão podem explorar questões emergentes, tais como o "potencial de comercialização de resíduo". Esse é um indicador que merece melhor consideração porque ao relacionar o total de Resíduo da Lagoa de Tratamento (RLT) comercializado com o total de fertilizantes produzidos, se tem uma visão da aplicabilidade de um material que, para empresas concorrentes, apresenta considerável complexidade para seu descarte.

O tratamento do resíduo apresenta-se, dessa forma, com potencial de tornar-se um diferencial competitivo no sistema estratégico da qualidade, tendo em vista que os concorrentes não promovem ações para sua reutilização.

Ao final desse estudo a empresa havia recebido a aprovação da Convenção-Quadro das Nações Unidas para Mudança do Clima (UNFCCC) para seu projeto de redução de até $80 \%$ na emissão gasosa de óxido nitroso (N2O) em seu Complexo Industrial de Piaçaguera, em Cubatão, permitindo à companhia comercializar mais de 687 mil créditos de carbono (CERs) até 2012 conforme prevê o Mecanismo de Desenvolvimento Limpo (MDL).

Como se pode verificar são muitas as oportunidades que se pode obter de um Alinhamento Estratégico que considere indicadores integrados de gestão ambiental e estratégica que podem ser evidenciados a partir de processos já implantados e em funcionamento nas empresas. 


\section{REFERÊNCIAS}

AMARATUNGA, D.; BALDRY, D. Moving from performance measurement to performance management. Facilities, v. 20, n. 5-6, p. 217-223, 2002.

ANASTAS P. T. e. FARRIS C. A, American Chemical Society, ACS Symposium Series, 577, 123, 1994.

ANDRADE, R. O. B.; TACHIZAWA, T.; CARVALHO, A. B. Gestão ambiental: enfoque estratégico aplicado ao desenvolvimento sustentável. São Paulo: Makron Books, 2000.

BADUE, A. F. B., MAIMON, D., SINGER, E. Gestão ambiental: compromisso da empresa. Gazeta Mercantil, São Paulo, mar./maio 1996.

BEAL, R. M.; YASAI-ARDEKANI, M. Performance implications of aligning CEO functional experiences with competitive strategies. Journal of Management, v.26, n. 4, p. 733-762, 2000.

BELINK, A. Termos e Definições. 2006. Disponível em: http://www.ethos.org.br/_Uniethos/documents/Apresentacao_28_06_associados.pdf

BERNARDI, L. A. Manual de Empreendedorismo e Gestão: fundamentos, estratégias e dinâmicas. São Paulo: Atlas, 2003.

CARVALHO; MMC; PALADINI, E.P. Gestão da Qualidade: Teoria e Casos. Ed Campus., 2006.

CASTRO, N.; SETTI, A. A.; GORGONIO, A. S.; REEBERG, J. H.; FARIA, S. C. A questão ambiental e as empresas. Brasília: SEBRAE, 2004.

CORDEIRO, J. V. B. de M. Alinhamento estratégico: estudos multicasos em empresas paranaenses de médio porte. 2005. 300f. Tese (Doutorado em Engenharia de Produção). Universidade Federal de Santa Catarina, Florianópolis,2005.

CULEY, Willian C. Environmental And Quality Systems Integration, Lewis Publisher: Washington, 1998.D'Avignon, 1994.

DENTON, D. K. Measuring relevant things, International Journal of Productivity and Performance Management, v. 54, n. 4, p. 278-287, 2005.

ENSSLIN, L.; MONTIBELlER, G. N.; NORONHA, S. M. - Apoio à Decisão: Metodologias para Estruturação de Problemas e Avaliação Multicritério de Alternativas - Ed. Insular: 2001. 295p., 2001

ENSSLIN, L.; ENSSLIN, S.R.; DUTRA, A.; PETRI, S.M. Identificando e analisando problemas de performance: o uso da avaliação de desempenho (Feedback, Coaching e Counseling) para melhorar a produtividade dos empregados. (Apostila da disciplina EPS 7007 - Avaliação de Desempenho; $1^{\circ}$ semestre, 2007; Florianópolis - UFSC, 2007.

FERREIRA, N.A.C. Empresas multinacionais e o estabelecimento de padrão ambiental corporativo global: A indústria de matérias-primas para fertilizantes. Dissertação (Mestrado em Desenvolvimento Regional e Meio Ambiente). Centro Universitário de Araraquara (UNIARA), 2006.

FONSECA JÚNIOR, W. C. Análise de conteúdo. In: DUARTE, Jorge; BARROS, Antônio (Org.). Métodos e técnicas de pesquisa em comunicação. São Paulo: Atlas, 2005. p. 290-303.

FRANCO, T. Padrões de produção e consumo nas sociedades urbano-industriais e suas relações com a degradação da saúde e do meio ambiente. In MINAYO, Maria Cecília de Souza (org.) Saúde e ambiente sustentável: estreitando nós. Rio de Janeiro: Editora FIOCRUZ, 2002.

GUBA, E.G. e LINCOLN, Y.S. Effective Evaluation. San Francisco, Ca., Jossey-Bass, 1981. HILL, R. P.; STEPHENS, D.; SMITH, I. Corporate Social Responsibility: An Examination of Individual Firm Behavior. Business \& Society Review. 1974. Fall 2003, Vol. 108. Issue 3, 2003. 


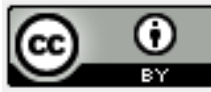

HURTADO, M. E. Os consumidores e a ISO 14000. Debates Socioambientais, v. 2, n. 5, p. 8-10, 1996/7.

HUTTNER, M.D., MOREIRA, J.S. Avaliação ambiental e epidemiológica do trabalhador da indústria de fertilizantes de Rio Grande, RS. Jornal de Pneumologia. Vol. 26, n5 1-18, 2000.

INSTITUTO ETHOS. Indicadores Ethos de Responsabilidade Social Empresarial 2005. São Paulo: Instituto Ethos, 2005.

JURAN, J.M. Controle da qualidade. São Paulo: Makron, 1991.

KEENEY, R. L. Value-focused thinking: a path to creative decisionmaking. Harvard University Press, London, 1992.

KOTLER, P.; ARMSTRONG, G. Princípios de Marketing. Tradução por: Arlete Símile Marques e Sabrina Cairo. 9. ed. 1. re. São Paulo: Prentice Hall, 2004.

LABOVITZ, G. e ROSANSKY, V.The Power of Alignment: how great companies stay centered and accomplish extraordinary things. USA: John Wiley e Sons, 1997.

LAYRARGUES, P. P. Educação para a gestão ambiental: a cidadania no enfrentamento político dos conflitos socioambientais. In: LOUREIRO, C. F. B. (Org.). Sociedade e meio ambiente: a educação ambiental em debate. São Paulo: Cortez, 2000.

LOPES, M.A.B. Fosfertil. 10 anos. Uberaba; Fosfertil, 1988.

LUDKE, M. e ANDRÉ, M. Pesquisa em educação: abordagens qualitativas. São Paulo: EPU, 1986.

MAIMON, Dalia. Passaporte Verde: Gerência Ambiental e Competitividade. Rio de Janeiro: Qualitymark,1996.

MAY, P.; LUSTOSA, M. C.; VINHA, V. Economia do meio ambiente. Rio de Janeiro: Campus, 2003.

MILES, M.B.; HUBERMAN, A. M. Qualitative data analysis: an expanded sourcebook California: Sage, 1994.

MILES, R. E.; SNOW, C. C. Designing Strategic Human Resource Systems. Organizational Dynamics, v. 13, n. 1, p. 36-52. 1984.

Mineiro, P. ISO 14.000- Nova era para a qualidade Ambiental. In: Ecologia e Desenvolvimento, p.. 4-15, ano 5. Set./Out., 1996.

MOURA, L.A.A. Qualidade e Gestão Ambiental. São Paulo: Juarez de Oliveira, 2004.

NAHUZ , M. R. O Sistema ISO 14000 e a certificação ambiental. Revista de Administração Empresas. FGV, v. 35, no 6, p.55-66; nov./dez., 1995.

NEELY, A.; POWEL, S. The challenges of performance measurement, Management Decision, v. 42, n.8, p. 1017-1023, 2004.

NEELY, A; GREGORY, M.; PLATTS, K. Performance measurement system design: a literature review and research agenda, International Journal of Operations \& Production Management, v. 25, n. 12, p. 1228-1263, 2005.

NOGUEIRA, A. C. L. Agricultura: o mercado de fertilizantes no Brasil. Disponível em: <http://www.acionista.com.br/>. Acesso em: 07 ago. 2009.

OLIVEIRA D. C. Análise de conteúdo temática: uma proposta de operacionalização. Texto didático e instrumentos. Rio de Janeiro: Universidade do Estado do Rio de Janeiro; 2004.

PALADINI, E. P. Avaliação estratégica da qualidade. São Paulo: Atlas, 2002.

PALADINI, E. P. Gestão da qualidade: teoria e prática. 2 ed. São Paulo: Atlas, 2004.

PALADINI, E. P. Gestão estratégica da qualidade - princípios, métodos e processos. São Paulo: Atlas, 2008.

PEREIRA, L. C.; TOCChetTO, M. R. L. Sistema de Gestão e Proteção Ambiental. Disponível em: http://www.gestaoambiental.com.br/articles.php?id=43 - Acesso em: 29.Jul. 2009.

PORTER, M. What is strategy? Harvard Business Review, p.61-78, Nov./Dec. 1996. 
PORTER, M. Competição: estratégias competitivas essenciais. 9 ed. Rio de Janeiro: Campus, 1999.

PRIETO, V. C. Análise de modelos de alinhamento estratégico interno. Dissertação (Mestrado em Engenharia de Produção). Programa de pós graduação em Engenharia de Produção. Escola Politécnica da Universidade de São Paulo. Departamento de Engenharia de Produção, São Paulo: 2006.

PRIETO, V. C.; CARVALHO, M. M. Análise do Alinhamento Estratégico e o Impacto nos Resultados no Setor de Medicina Diagnóstica. In: Encontro da Associação Nacional de PósGraduação e Pesquisa em Administração, 28, 2004, Curitiba, 2004. Anais ANPAD, 2004. REIS, Maurício J. L. ISO 14000 - Gerenciamento Ambiental. Editora Qualitymark, Rio de Janeiro, 200 p., 1995.

ROBLES Jr., A.; BONELLI, V. V. Gestão da qualidade e do meio ambiente - enfoque econômico, financeiro e patrimonial. São Paulo: Atlas, 2006.

SCHENINI. P. C. Avaliação dos padrões de competitividade à luz do desenvolvimento sustentável: o caso da Indústria Trombini Papel e Embalagens S/A em Santa Catarina Brasil. Tese (Doutorado em Engenharia de Produção). Centro Tecnológico, Universidade Federal de Santa Catarina. Florianópolis, 1999.

SKINNER, W. The productivity paradox. Management Review, 75, 41-45, 1986.

TACHIZAWA, T. Gestão ambiental e responsabilidade social corporativa. São Paulo: Atlas, 2002.

TAGUCHI, G. Introduction to quality engineering: designing quality into products and processes. Tokyo: Asian Productivity Organization, 1990.

TANGEN, S. An overview of frequently used performance measures, Work Study, v. 52, n. 7, p. 347-354, 2003.

TIBOR, T. \& FELDMAN, I. ISO 14000: um guia para as novas normas de gestão ambiental. São Paulo, Futura, 1996.

TIGRE, Paulo B. (coord.). Tecnologia e meio ambiente: oportunidades para a indústria. Rio de Janeiro: UFRJ, 1994.

VALLE, C. E. Qualidade Ambiental: O desafio de ser competitivo protegendo o meio ambiente. São Paulo: Pioneira, 2005.

WEISS, C. Produits verts: que choisir? Calypso Log, v.165, p. 12-4, 1997.

YIN, R. K. (2002). Estudo de caso. Planejamento e métodos. Porto Alegre: 1994. 